\title{
Sodium dodecyl sulfate allows the persistence and recovery of biofilms of Pseudomonas fluorescens formed under different hydrodynamic conditions
}

\author{
Manuel Simões*, Lúcia C. Simões, Maria O. Pereira and Maria J. Vieira \\ IBB - Institute for Biotechnology and Bioengineering, Centre for Biological Engineering, Universidade do Minho, Campus de \\ Gualtar, 4710-057 Braga, Portugal
}

(Received 27 July 2007; final version received 2 October 2007)

\begin{abstract}
The effect of the anionic surfactant sodium dodecyl sulfate (SDS) on Pseudomonas fluorescens biofilms was investigated using flow cell reactors with stainless steel substrata, under turbulent $(\operatorname{Re}=5200)$ and laminar $(\mathrm{Re}=2000)$ flow. Steady-state biofilms were exposed to $\mathrm{SDS}$ in single doses $(0.5,1,3$ and $7 \mathrm{mM})$ and biofilm respiratory activity and mass measured at $0,3,7$ and $12 \mathrm{~h}$ after the SDS application. The effect of SDS on biofilm mechanical stability was assessed using a rotating bioreactor. Whilst high concentrations $(7 \mathrm{mM})$ of SDS promoted significant biofilm inactivation, it did not significantly reduce biofouling. Turbulent and laminar flow-generated biofilms had comparable susceptibility to SDS application. Following SDS exposure, biofilms rapidly recovered over the following $12 \mathrm{~h}$, achieving higher respiratory activity values than before treatment. This phenomenon of posttreatment recovery was more pronounced for turbulent flow-generated biofilms, with an increase in SDS concentration. The mechanical stability of the biofilms increased with surfactant application, except for SDS concentrations near the critical micellar concentration, as measured by biofilm removal due to an increase in external shear stress forces. The data suggest that although SDS exerts antimicrobial action against $P$. fluorescens biofilms, even if only partial and reversible, it had only limited antifouling efficacy, increasing biofilm mechanical stability at low concentrations and allowing significant and rapid recovery of turbulent flow-generated biofilms.
\end{abstract}

Keywords: biofilm mechanical stability; persistence; recovery; resistance; surfactant; turbulent flow; laminar flow

\section{Introduction}

The structure, composition and physiology of microbial biofilms have become inevitably linked with man's failure to control them by the conventional treatments that are effective against suspended bacteria (Chen and Stewart 2000; Donlan and Costerton 2002; Gilbert et al. 2002; Fux et al. 2005; Perez-Roa et al. 2006). Bacteria in biofilms have intrinsic mechanisms that protect them from even the most aggressive environmental conditions, namely the exposure to chemical antimicrobials. Furthermore, there is no answer to why and how bacteria, growing within a biofilm, develop increased resistance to antimicrobial agents. Despite this uncertainty, there are five hypotheses concerning mechanisms: (i) direct interactions between the biofilm extracellular polymeric matrix constituents and antimicrobials, which affects diffusion and availability; (ii) an altered chemical microenvironment within the biofilm leading to areas of reduced or no growth; (iii) the development of biofilm/attachment-specific phenotypes; (iv) the possibility of damaged bacterial cells undergoing apoptosis or programmed cell death; (v) persister cells (Cloete et al. 1998; Lewis 2001; Mah and
O'Toole 2001; Pereira and Vieira 2001; Spoering and Lewis 2001; Davies 2003; Stewart 2003). The persistent cellular state is the newest explanation for biofilm insusceptibility to antimicrobial agents (Lewis 2001; Sufya et al. 2003), since the conventional explanation of transport limitation and chemical interaction with biofilm constituents does not always explain the recalcitrant properties of biofilms. The environmental conditions under which biofilms are formed influence significantly biofilm phenotype and their insusceptibility to conventional control strategies (Simões et al. 2005a, 2007; McDougald et al. 2006). For instance, several studies (Vieira et al. 1993; Pereira et al. 2002; Simões et al. 2007) reported that turbulent flowgenerated biofilms had a distinct structure, greater mass, metabolic activity and total protein content in comparison to their laminar counterparts. Other authors (Boyle and Lappin-Scott 2006, 2007) also demonstrated that progressively increasing the flow rate from laminar to turbulent had an escalating effect on the attachment of pseudomonad cells to glass.

As a means of controlling biofilms, industry has moved progressively towards the use of more

\footnotetext{
*Corresponding author. Email: mjvsimoes@deb.uminho.pt 
biodegradable and less toxic compounds, such as surface active compounds, i.e. surfactants (MacDonald et al. 2000). These are used both to prevent attachment of microorganisms with the potential to form biofilms and to promote the detachment of microorganisms from the surface without disturbing the environment and safeguarding human well-being (MacDonald et al. 2000; Simões et al. 2006). Such compounds act as multi-target agents against the bacterial cells, altering the surface properties of the submerged surfaces and decreasing their surface tension (Jönsson et al. 1998). Anionic surfactants possess strong detergent and biocidal properties, with the outer and cytoplasmic membranes and the membrane-bound enzyme functions being the main targets (Denyer and Stewart 1998).

This work reports a study to determine the control effects of sodium dodecyl sulfate (SDS), an anionic surfactant widely used in detergent formulations, against $P$. fluorescens biofilms formed under diverse hydrodynamic stresses.

\section{Materials and methods}

\section{Microorganism and cell growth}

Pseudomonas fluorescens ATCC $13525^{\mathrm{T}}$, obtained from the American Type Culture Collection and preserved in cryovials (Nalgene) at $-80 \pm 2^{\circ} \mathrm{C}$, was used throughout this study. The growth conditions were $27 \pm 2^{\circ} \mathrm{C}$, pH $7.0 \quad(0.02 \mathrm{M}$ phosphate buffer $\mathrm{KH}_{2} \mathrm{PO}_{4} ; \mathrm{Na}_{2} \mathrm{HPO}_{4}$ ), with glucose, yeast extract and peptone as nutrients.

The bacterial culture was grown in a 0.51 glass chemostat (Quickfit, MAF4/41, England), at $27^{\circ} \mathrm{C}$, aerated (air flow rate $=0.4251 \mathrm{~min}^{-1}$ ) and agitated (Heidolph $\mathrm{Mr}$ 3001) with a magnetic stirrer, and continuously fed, at a flow rate of $10 \mathrm{ml} \mathrm{h}^{-1}$, with a sterile concentrated nutrient solution consisting of $5 \mathrm{~g}^{-1}$ glucose, $2.5 \mathrm{~g}^{-1}$ peptone and $1.25 \mathrm{~g}^{-1}$ yeast extract, prepared in phosphate buffer at $\mathrm{pH} 7$ $(0.02 \mathrm{M})$. All the medium components were purchased from Merck (VWR, Portugal).

$P$. fluorescens was used as a model microorganism since it is ubiquitous and has the potential to cause serious problems in industrial environments, in both its planktonic and biofilm states (Wiedmann et al. 2000; Simões et al. 2007). This bacterium also possesses a strong ability to originate disinfectant-resistant biofilms (Simões et al. 2003a, 2005a).

\section{Surfactant}

The anionic surfactant sodium dodecyl sulfate (SDS), purchased from Riedel-de-Haën (Cat. No. 62862; critical micellar concentration, $8.30 \mathrm{mM}$ ), was used at concentrations of $0.5,1,3$ and $7 \mathrm{mM}$, prepared with sterile distilled water.

\section{Surfactant neutralization}

The neutralization solution was prepared using the following reactants $(\mathrm{w} / \mathrm{v}) 0.1 \%$ peptone, $0.5 \%$ Tween 80 and $0.07 \%$ lecithin, in $0.02 \mathrm{M}$ phosphate buffer $\mathrm{pH}$ 7 (Johnston et al. 2002). A concentrated neutralization solution was prepared and autoclaved prior to utilization. The neutralization reaction was allowed to proceed for $10 \mathrm{~min}$. Control experiments showed that there was no interference between the neutralization method and bacterial viability and metabolic activity.

\section{Biofilm system}

A continuous culture of $P$. fluorescens in the exponential phase of growth in a 0.51 glass chemostat was used to continuously inoculate a 3.51 Perspex (polymethyl methacrylate) reactor that was aerated (air flow rate $=0.2431 \mathrm{~min}^{-1}$ ) and agitated. This reactor was fed with a minimal nutrient medium $(0.05 \mathrm{~g}$ glucose $1^{-1}, 0.025 \mathrm{~g}$ peptone $1^{-1}$ and $0.0125 \mathrm{~g}$ yeast extract $1^{-1}$ in $0.02 \mathrm{M}$ phosphate buffer, $\mathrm{pH} 7$ ), at a flow rate of $1.71 \mathrm{~h}^{-1}$, supporting a bacterial cell density of approximately $6 \times 10^{7}$ cells $\mathrm{ml}^{-1}$.

A continuous flow cell reactor, described in detail by Pereira et al. (2002), was used for biofilm formation by $P$. fluorescens. It consisted of a semi-circular Perspex duct with several apertures on its flat face to fit several coupons to which biofilm formation surfaces $(1.75 \times 1.25 \mathrm{~cm})$ were glued. In the present study, these surfaces were ASI 316 stainless steel slides.

Biofilms were formed by recirculating (Eheim Typ 1060 and Eheim Typ 1048 centrifugal pumps) the bacterial suspension, obtained from the 3.51 reactor through two similar flow cell reactors operating in parallel, each with 10 stainless steel slides for biofilm formation. One of the flow cells was used to promote turbulent flow $\left(\operatorname{Re}=5200, \mathrm{u}=0.532 \mathrm{~m} \mathrm{~s}^{-1}\right)$ and the other laminar flow $\left(\operatorname{Re}=2000, \mathrm{u}=0.204 \mathrm{~m} \mathrm{~s}^{-1}\right)$. The biofilms were allowed to grow for 7 days to ensure that steady-state biofilms were used in every experiment (Pereira et al. 2002).

\section{Flow-generated biofilm tests}

The biofilms formed on the metal slides of each flow cell reactor were exposed to different concentrations of SDS for $30 \mathrm{~min}$. This biofilm-SDS exposure time was selected on the basis of previous biofilm control experiments (Simões et al. 2003b, 2005a). Each SDS concentration was tested in an independent experiment and each experiment was performed on three separate 
occasions. During the treatment period, an SDS solution replaced the diluted bacterial suspension flowing in the flow cell reactors. This was performed using independent sterile flasks containing 11 of SDS solution for each flow cell. The flow was only interrupted for $30 \mathrm{~s}$ before starting the SDS treatment to allow the careful opening of the valve that permits the circulation of SDS solution and the careful closure of the valve of the tube allowing bacterial suspension flow. After the exposure time to SDS, the flow of the surfactant solution through the flow cells was stopped, carefully drained from the flow cell reactors and the bacterial suspension re-introduced in the system to restore the conditions prior to surfactant application and to mimic real industrial situations (Simões et al. 2005a). Control experiments were performed using $0.02 \mathrm{M}$ phosphate buffer $(\mathrm{pH} 7)$ instead of SDS, allowing an accurate comparative assessment of SDS action on biofilms.

In each experiment, and prior to the beginning of surfactant treatment, two metal slides of each flow cell, operating in parallel, were sampled and used as controls. Immediately after the 30-min surfactant treatment (time zero), two of the metal slides from each flow cell were also sampled, according to the procedure described by Pereira et al. (2002). To assess whether time plays a significant role in the action of SDS in preventing subsequent biofilm growth, the remaining biofilm-covered slides were left in the flow cells and sampled 3, 7 and $12 \mathrm{~h}$ after surfactant application. For every condition tested, and for all sampling times, two stainless steel slides were used. The biofilms covering the stainless steel slides were completely scraped off (as verified by epifluorescence microscopic visualization using 4,6-diamino-2-phenylindole [DAPI] staining - results not shown), resuspended in $10 \mathrm{ml}$ of neutralization solution and left for 10 min. After SDS neutralization, the biofilm suspensions were vortexed (Heidolph, model Reax top) for $30 \mathrm{~s}$ with $100 \%$ input, washed twice with saline phosphate buffer, resuspended in phosphate buffer and immediately used to assess the bacterial respiratory activity. Afterwards, the suspensions were used to determine biofilm mass.

\section{Biofilm mechanical stability}

The mechanical stability of $P$. fluorescens biofilms was assessed by determining the loss of biomass due to the exposure of biofilms to agitation at an increasing Reynolds number $\left(\mathrm{N}^{\prime} \mathrm{Re}_{\mathrm{A}}\right)$ in a rotating bioreactor. This device, consisting of a 3.51 reactor (diameter $=$ $16.8 \mathrm{~cm}$ ), containing three suspended and immersed stainless steel cylinders under rotation, has already been used to evaluate the mechanical stability of biofilms with and without exposure to antimicrobial agents (Simões et al. 2003a, 2003b). Biofilms were developed on the three ASI 316 stainless cylinders (surface area $=34.6 \mathrm{~cm}^{2}$ ), under a $\mathrm{N}^{\prime} \mathrm{Re}_{\mathrm{A}}$ of 2400 , inserted in the 3.51 reactor, operating under the same conditions as the flow cells (same growth medium, dilution rate, $\mathrm{pH}$ and temperature), according to the procedure described by Simões et al. (2005b). After 7 days of operation, the cylinders covered with biofilm were carefully removed from the reactor. One of the cylinders was immersed in another reactor with phosphate buffer while the others were immersed for $30 \mathrm{~min}$ in reactors containing SDS solutions of different concentrations (volume of each reactor, $170 \mathrm{ml}$ ). The exposure to the surfactant was also carried out with the cylinders rotating at a $\mathrm{N}^{\prime} \mathrm{Re}_{\mathrm{A}}$ of 2400. Immediately after treatment, each cylinder was removed from the reactors containing the SDS solutions, accurately weighed, re-introduced in the reactor filled with $0.02 \mathrm{M}$ phosphate buffer, and consecutively subjected to serial $\mathrm{N}^{\prime} \mathrm{Re}_{\mathrm{A}}$, ie 4000 , $8100,12,100$ and 16,100 , for a period of $30 \mathrm{~s}$ each. The experiments were repeated on three different occasions for every surfactant concentration tested.

The quantification of the final wet mass of the biofilm that remained attached to each cylinder after submission to the complete $\mathrm{N}^{\prime} \mathrm{Re}_{\mathrm{A}}$ series was measured as the difference between the combined weight of the cylinder plus biofilm and the weight of the respective clean cylinder obtained before its introduction in the 3.51 reactor (Simões et al. 2005b). The same procedure was followed with the control assay (untreated biofilms), i.e. with the cylinder plus biofilm immersed in the $0.02 \mathrm{M}$ phosphate buffer solution.

Biofilm removal from each cylinder, after exposure to the full series of $\mathrm{N}^{\prime} \mathrm{Re}_{\mathrm{A}}$, was expressed as percentage according to the following equation:

$$
\begin{aligned}
& \text { Biofilm removal }(\%) \\
& \quad=\left(W_{\mathrm{AT}}-W_{\mathrm{TSR}}\right) /\left(W_{\mathrm{AT}}-W_{\mathrm{C}}\right) \times 100
\end{aligned}
$$

where $W_{\text {TSR }}$ is the biofilm mass plus cylinder after submission to the total $\mathrm{N}^{\prime} \mathrm{Re}_{\mathrm{A}}$ series $(\mathrm{g}), W_{\mathrm{AT}}$ is the wet biofilm mass plus cylinder after SDS treatment for $30 \mathrm{~min}(\mathrm{~g})$ and $W_{\mathrm{C}}$ is the wet mass of the clean cylinder, i.e. without adhered biofilm (g).

\section{Respiratory activity assessment}

The respiratory activity of biofilm suspensions was evaluated by measuring the oxygen uptake rate needed to oxidise glucose in a biological oxygen monitor (BOM) in short-term assays and expressed as $\mathrm{mgO}_{2}$ $\mathrm{g}^{-1}$ biofilm $\mathrm{min}^{-1}$. The assays were performed in a Yellow Springs Instruments BOM (Model 53) 
following the procedure described previously (Simões et al. 2005c). In biofilms, metabolic activity may reflect biofilm bacteria that are still viable, even though they may not show signs of viability such as the capability to grow in a solid medium. Whenever biofilms are the issue, assessment of respiratory activity due to oxygen uptake rate may be more accurate than the traditional method of colony formation on agar media to assess the viability of bacteria (Simões et al. 2005c).

The decrease in bacterial activity obtained due to the application of the different concentrations of SDS to $P$. fluorescens biofilms was determined as the difference between the respiratory activities of the samples before (control) and immediately after the treatment period with SDS and expressed as the percentage of inactivation according to the following equation:

$$
\text { Inactivation }(\%)=\left[\left(A_{0}-A_{1}\right) / A_{0}\right] \times 100
$$

where $A_{0}$ is the respiratory activity of the control assay, i.e. without SDS treatment, and $A_{1}$ is the respiratory activity immediately after the application of each SDS concentration.

\section{Biofilm mass}

The dry mass of the biofilm accumulated on the slides after the respiratory activity determination was assessed by the determination of the total volatile solids (TVS) of the homogenised biofilm suspensions, according to Standard Methods (American Public Health Association [APHA], American Water Works Association [AWWA], Water Pollution Control Federation [WPCF], 1989), method number 2540 A-D. According to this methodology, the TVS after exposure to a temperature of $550 \pm 5^{\circ} \mathrm{C}$ in a furnace (Lenton thermal designs) for $2 \mathrm{~h}$ is equivalent to the amount of biological mass. The biofilm mass accumulated was expressed in $\mathrm{mg}$ of biofilm $\mathrm{cm}^{-2}$ of surface area of the slide (mg biofilm $\mathrm{cm}^{-2}$ ).

The percentage of biofilm removal was determined using the following equation:

$$
\text { Biofilm removal }(\%)=\left[\left(W_{0}-W_{1}\right) / W_{0}\right] \times 100
$$

where $W_{0}$ is the biofilm mass without surfactant application and $W_{1}$ is the biofilm mass after SDS treatment.

\section{Biofilm staining with a viability stain}

P. fluorescens biofilms were stained with L-7012 Live/ $\operatorname{Dead}^{\mathbb{R}}(\mathrm{L} / \mathrm{D})$ BacLight ${ }^{\mathrm{TM}}$ Bacterial Viability kit (Molecular Probes Cat. No. L-7012, Leiden,
Netherlands) and visualised by epifluorescence microscopy, according to the procedure described by Simões et al. (2005c). Viable cells fluoresce green, non-viable cells fluoresce red and injured cells fluoresce orange and yellow.

\section{Statistical analysis}

The data were analysed using the statistical program SPSS 14.0 (Statistical Package for the Social Sciences). The mean and standard deviation within samples were calculated. Paired $t$-test analyses were performed for data assuming a normal distribution. Other data were statistically analyzed by the nonparametric Wilcoxon test. Statistical calculations were based on confidence level equal or higher than 95\% $(P<0.05$ was considered statistically significant).

\section{Results \\ Evaluation of SDS effect on turbulent and laminar flow-generated biofilms}

The effect of SDS application for $30 \mathrm{~min}$ against biofilms formed on the stainless steel slides under turbulent and laminar flow was assessed either by determining respiratory activity or biofilm mass. The results, presented in terms of percentage of biofilm inactivation (Figure 1a) and removal (Figure 1b), were obtained immediately after SDS application. Respiratory activity and the mass of turbulent flowgenerated biofilms were much higher than those of laminar flow-generated biofilms (as can be seen in Figures 2 and 4 for the control experiments, ie without SDS application). These differences are inherent to the characteristics of the flow and have been documented in a previous report (Simões et al. 2007).

Figure 1a shows that SDS promoted biofilm inactivation, the effect being dependent on the concentration since inactivation increased with higher concentrations of SDS $(P<0.05)$. However, in the range of concentrations tested, total inactivation was not achieved, emphasizing that immediately after the 30 min SDS treatment, both types of biofilms still showed respiratory activity. Moreover, the comparison between inactivation values of turbulent and laminar flow-generated biofilms showed that both biofilms had similar susceptibility to SDS action $(P>0.1)$.

According to Figure 1b, SDS had a poor effect on biofilm removal for both types of biofilms. In almost all the experiments (except for $3 \mathrm{mM}$ and for laminar flow-generated biofilms) removal was $<15 \%$, confirming the recalcitrant properties of biofilms exposed to SDS. Removal was not 


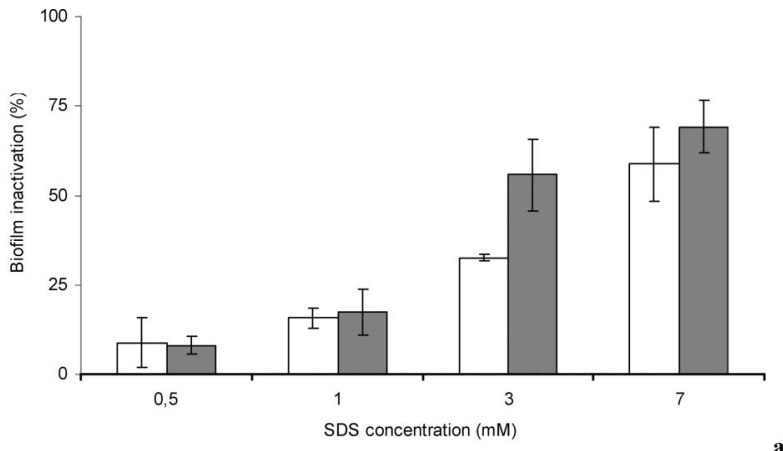

a)

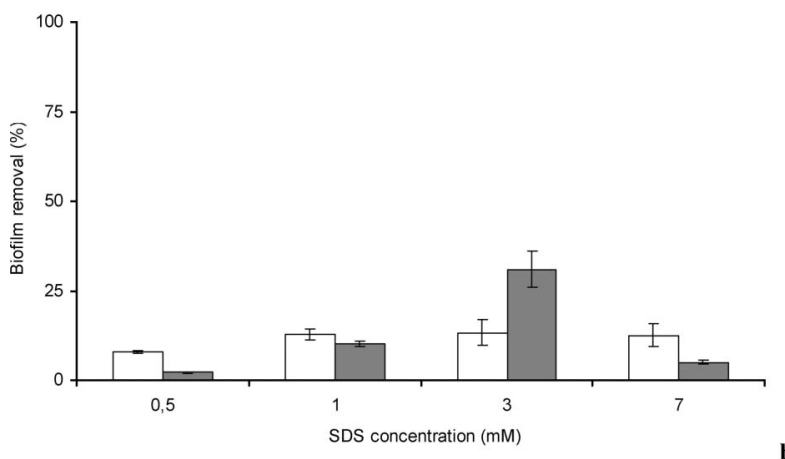

b)

Figure 1. Inactivation (a) and removal (b) of turbulent ( $\square$ ) and laminar ( $\square$ ) flow-generated biofilms as a function of SDS concentration. Each symbol indicates the mean \pm SD of three independent experiments.

dependent on the surfactant concentration since an increase of SDS concentration did not increase biofilm removal $(P>0.1)$. Statistical analysis of data for turbulent and laminar flow-generated biofilms revealed equivalent removal in both cases $(P>0.05)$.

\section{Evaluation of post-surfactant action}

After SDS application, biofilms still showed signs of metabolic activity (Figure 2). This feature is more evident for the turbulent flow-generated biofilms and when exposed to 1,3 and $7 \mathrm{mM}$ of SDS and $12 \mathrm{~h}$ after treatment (Figure 2a), where biofilms exhibited respiratory activity values that were higher than in the control experiment $(P<0.05)$. The recovery of turbulent flow-generated biofilms was more pronounced for biofilms exposed to increasing concentrations of SDS $(P<0.05)$. Laminar flow-generated biofilms (Figure 2b) did not display significant recovery at the concentrations tested $(P>0.05)$. In the control experiments without surfactant, neither type of flow-generated biofilm showed any variation in respiratory activity with time $(P>0.1)$. The steady-state metabolism of these biofilms (Pereira et al. 2002) accounts for this constancy in respiratory

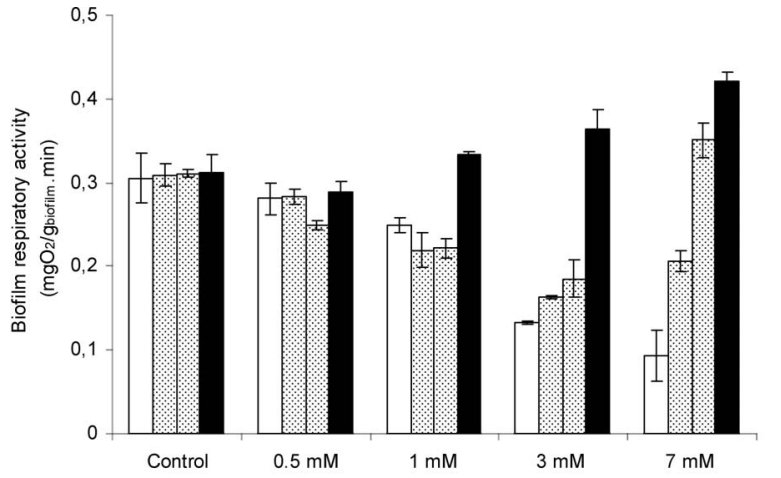

(a)

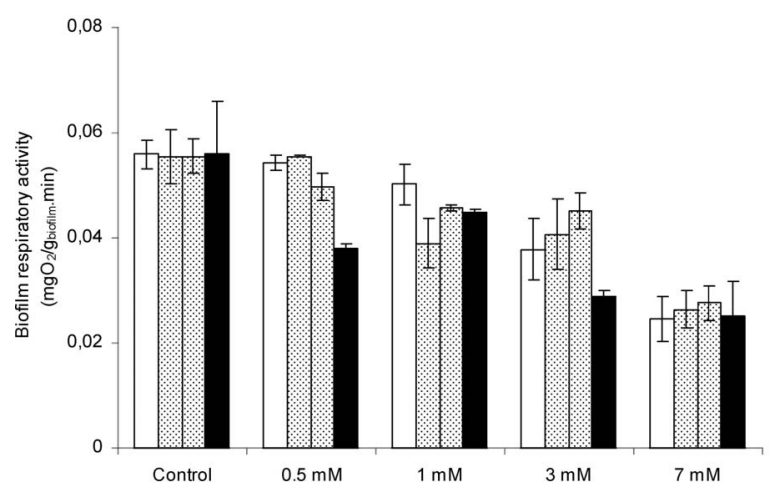

(b)

Figure 2. Biofilm respiratory activity after SDS treatment

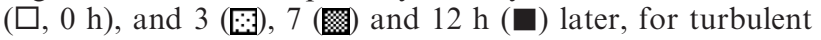
(a) and laminar (b) biofilms. Control = without surfactant treatment. Each symbol indicates the mean \pm SD of three independent experiments.

activity. The phenomenon of biofilm recovery was also evident when turbulent flow-generated biofilms treated with $3 \mathrm{mM}$ of SDS were stained with a viability stain and observed by epifluorescence microscopy (Figure 3). Figure 3 depicts the antimicrobial effect with SDS application, where the apparent proportion of viable cells (green) decreased significantly becoming non-viable (red) or injured (orange and yellow). However, the spatial amount of nonviable cells or injured cells clearly decreased $12 \mathrm{~h}$ after the treatment, increasing the proportion of viable cells. Thus, a significant part of the biofilm-entrapped bacteria remaining on the flow cells after SDS treatment recovered viability during the $12 \mathrm{~h}$ of the experiment.

Only small variations in biofilm mass were obtained in response to surfactant treatment (Figure 4). Statistical tests showed that the application of SDS and length of exposure $(>12 \mathrm{~h})$ did not promote any significant additional biofilm mass removal or increase for any conditions tested and for any sampling time $(P>0.05)$. 

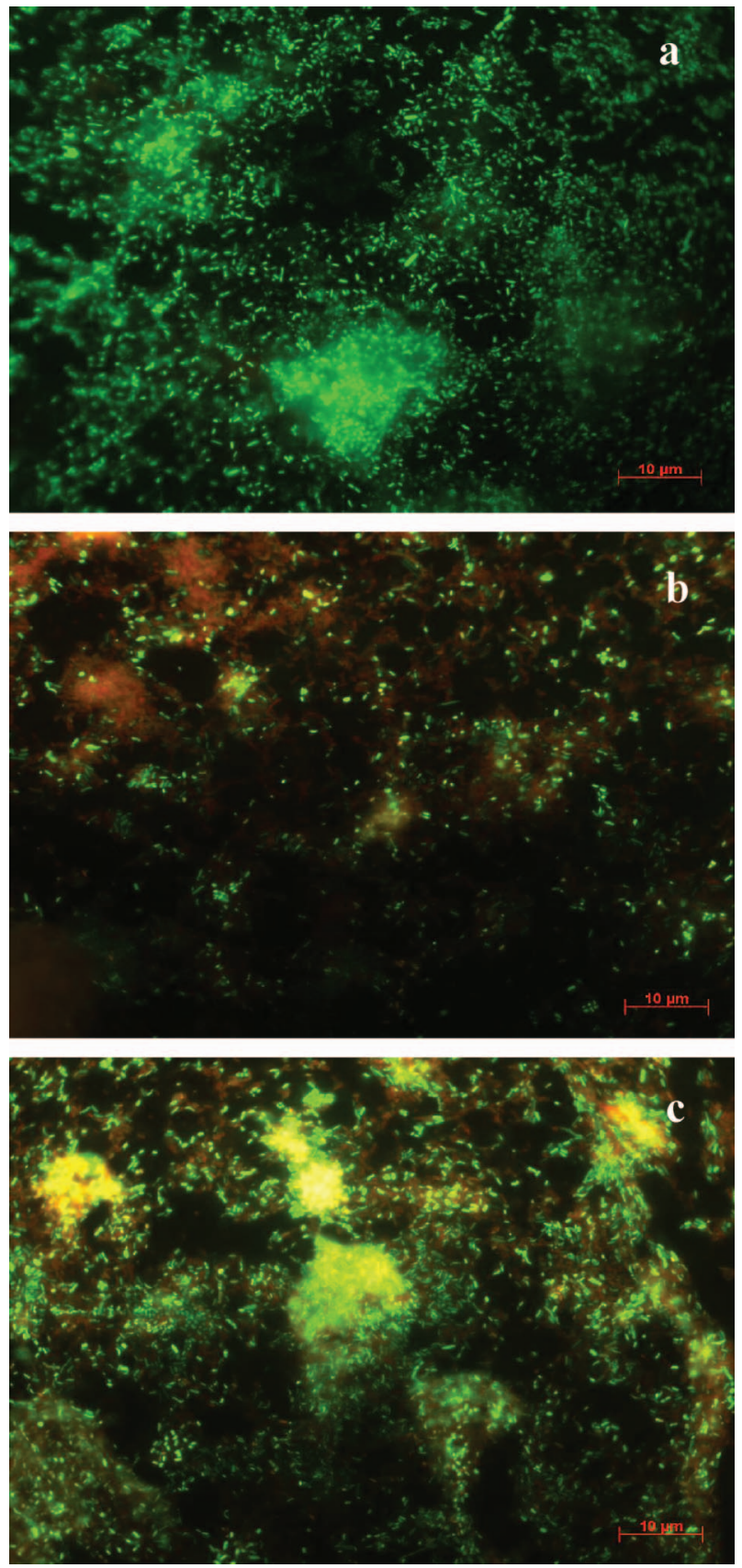

Figure 3. Epifluorescence photomicrographs of cells grown within turbulent biofilms, before treatment with $3 \mathrm{mM}$ SDS (a); immediately after treatment (b) and $12 \mathrm{~h}$ later (c). $\times 1320$ magnification; bar $=10 \mu \mathrm{m}$. Viable cells are green, nonviable are red and injured cells are orange and yellow.

\section{Mechanical stability of biofilms}

To obtain a deeper knowledge of the effect of SDS on biofilm removal, a series of experiments was carried out with the aim of characterizing the mechanical stability of biofilms in response to sudden changes of hydrodynamic conditions. The results, expressed in

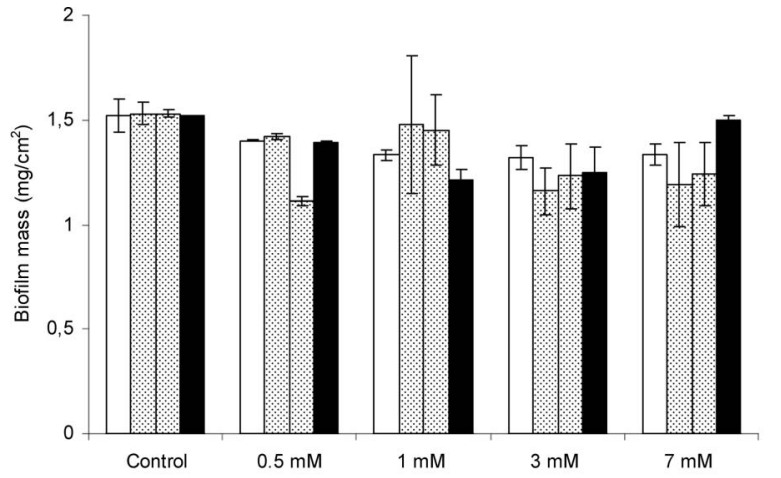

(a)

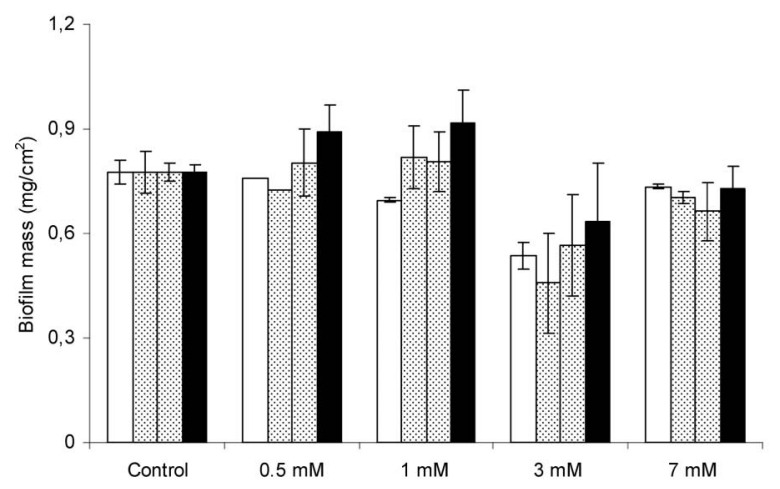

(b)

Figure 4. Biofilm mass after SDS treatment $(\square, 0 \mathrm{~h})$, and

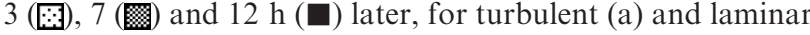
(b) biofilms. Control = without surfactant treatment. Each symbol indicates the mean \pm SD of three independent experiments.

terms of percentage of biofilm removal from the surface of the stainless steel cylinders, are displayed in Figure 5.

Hydrodynamic stress (exposure to increasing series of $\mathrm{N}^{\prime} \mathrm{Re}_{\mathrm{A}}$ ) promotes high biofilm removal $(75 \%$ of the total biofilm mass), which was altered when the biofilms were previously treated with SDS. The application of $0.5,1$ and $3 \mathrm{mM}$ SDS promoted biofilm cohesion since the percentages removed were smaller than those observed for the control experiment $(P<0.05)$. The application of $7 \mathrm{mM}$ SDS increased biofilm removal compared with other concentrations and with the control, resulting in removal of $>80 \%$ of the total biofilm mass. However, this difference was not significantly different from untreated biofilms $(P<0.05)$.

\section{Discussion}

Understanding how biofilms respond to external stress conditions is essential for the development of new biofilm control strategies. The present study has 


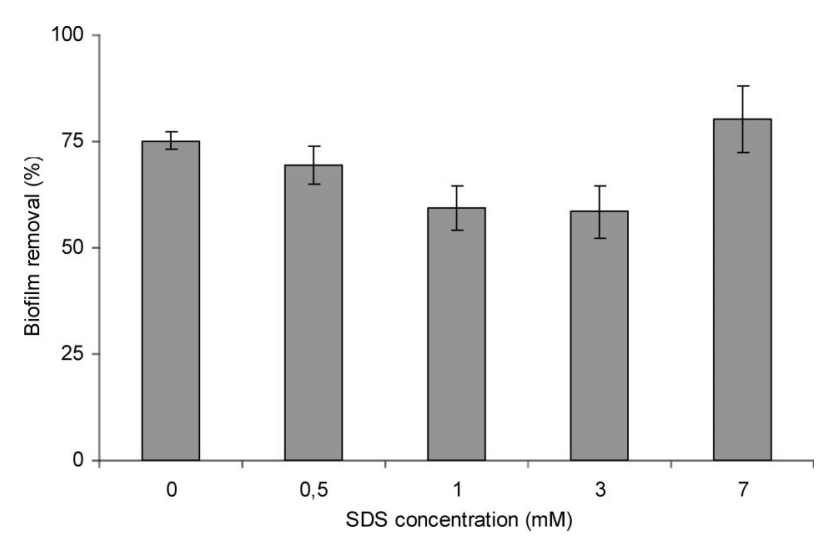

Figure 5. Percentage biofilm removal after submission to the $\mathrm{N}^{\prime} \mathrm{Re}_{\mathrm{A}}$ series. Each symbol indicates the mean $\pm \mathrm{SD}$ of three independent experiments.

implications for understanding the mode of action of SDS on biofilms with distinct phenotypes and potential resistance parameters that can affect strategies for biofilm control. Disinfection procedures are often designed based on experiments carried out with planktonic cultures. Such tests do not mimic the growth conditions found on surfaces where the antimicrobials are required to inactivate attached microorganisms (Simões et al. 2005a). Biofilm structure and the physiological attributes of biofilmentrapped microorganisms confer an inherent resistance to antimicrobial agents (Lewis 2001; Mah and O’Toole 2001; Spoering and Lewis 2001; Davies 2003; Stewart 2003) that cannot be overlooked.

A comparison of the action of SDS against biofilms formed under different hydrodynamic conditions showed that both turbulent and laminar flow-generated biofilms had similar susceptibility to the surfactant (Figure 1). The overall activity and mass results showed that the flow conditions under which the biofilms were formed played a significant role in terms of biofilm characteristics (Simões et al. 2007) but did not affect the activity of SDS in controlling the biofilm. In previous studies (Simões et al. 2003a, 2003b, 2005a) using aldehyde-based biocides and a cationic surfactant, it was demonstrated that laminar flow-generated biofilms were more easily inactivated than those formed under turbulent flow. Furthermore, turbulent flow-generated biofilms are known to have a higher cellular density than their laminar flow-generated counterparts, while the latter present a more complex matrix (Simões et al. 2007). The distinct phenotype of turbulent and laminar flow-generated biofilms (Simões et al. 2007) as well as diverse SDS-biofilm matrix electrostatic interactions, could be responsible for the observed results. The extracellular polymeric matrix of biofilms is mainly an anionic charged structure (Costerton et al. 1987), and thus electrostatic repulsion could exist between the anionic matrix and the surfactant, thereby decreasing the antimicrobial effect. This repulsion will be much more intense in laminar flow-generated biofilms, as the ones formed under turbulent flow are mainly composed of cells and almost no extracellular polymeric matrix (Simões et al. 2007). Biofilm physiology appears to be critical for the action of SDS since Chen and Stewart (2000) reported that $3.5 \mathrm{mM}$ SDS was moderately efficient in the removal of $P$. aeruginosa biofilm (removal between 63 and 79\%) even if the surfactant had a low effect on bacterial viability.

The ability of SDS to inactivate biofilms (Figure 1a) was greater than its ability to remove biofilms from surfaces (Figure 1b). The active pellicle left behind may constitute a source of additional problems such as biofilm recovery and regrowth, development of multiresistant biofilms or harbour for other microorganisms (Møretrø and Langsrud 2004; Lapidot et al. 2006). The survival of some bacterial cells following SDS treatment, verified by the post-surfactant treatment results, allowed biofilm regeneration and thus permitted recovery in terms of respiratory activity (Figure 2) and viability (Figure 3). Respiratory activity results were corroborated by the qualitative epifluorescence microscopy visualizations, documented for turbulent flow-generated biofilms exposed to $3 \mathrm{mM}$ of SDS (Figure 3). In a previous report (Simões et al. 2005c), a strong correlation between bacterial respiratory activity and viability measured by the L/D Baclight kit was found. The phenomenon of recovery post-surfactant treatment was more pronounced for turbulent flowgenerated biofilms and with the increasing concentration of SDS. This indicates that turbulent and laminar flow-generated biofilms present distinct characteristics and similar tolerance face to SDS exposure, but their behaviour after surfactant treatment was also distinct. These data have relevance to many industrial cleaning and disinfection flow-dependent processes. The occurrence of persistent cells is a phenomenon already described for several bacteria when exposed to standard antibiotics (Stewart 2003; Harrison et al. 2005). According to Stewart (2003), a reduced and reversible antimicrobial susceptibility could lead to populations of resistant bacteria, which may be recalcitrant to further disinfection processes. The potential for recovery from chemical treatment was remarkable in this study since the respiratory activity of the SDS-treated biofilms after $12 \mathrm{~h}$ was higher than for those observed without treatment (Figure 2). A more sustained antibacterial effect had been expected as the biofilms not immediately sampled after SDS application were not subjected to the surfactant 
neutralization step. Thus, the SDS retained within the biofilm structure had more chance to act on the bacteria. Forsythe and Hayes (1998) showed that surfaces treated with surfactants could retain a bacteriostatic film due to the adsorption of the chemical on the surface. This film would prevent the subsequent growth of residual bacteria. Nevertheless, data presented in this study indicated that SDS did not induce biofilm recovery suppression (Figures 2 and 3) or biofilm detachment (Figure 4) for both turbulent and laminar flow-generated biofilms. The apparent phenomenon involved in biofilm bacteria recovery is related to sub-lethal damage of the cellular membrane, which allows an increased uptake of nutrients following surfactant treatment (Simões et al. 2006). Marcotte et al. (2004) suggested that SDS disrupts the architecture of biofilms thereby allowing better diffusion of substances since SDS-biofilm interactions were reversed by fresh medium circulation. The data obtained, from the control experiments, also showed that recovery of $P$. fluorescens biofilm was neither a time dependent effect or due to the attachment of new cells since the parameters analysed did not show any significant variation with time. It is assumed that the steady-state of the biofilms were affected leading to a diverse recovery and to a new steady-state, depending both on the SDS concentration applied and the new biofilm phenotype conferred by SDS stress.

The reduced effect caused by SDS on biofilm removal is reinforced by the mechanical stability results where low SDS concentrations increased biofilm mechanical stability (Figure 5). Mechanical stability is an important factor in determining the structure and function of biofilm systems and this parameter plays a key role in the removal and/or control of biofilms in engineered systems (Mayer et al. 1999; Poppele and Hozalski 2003). So far, only limited studies have been conducted on the mechanical stability of biofilms (Ohashi and Harada 1994, 1996; Ohashi et al. 1999; Stoodley et al. 1999; Körstgens et al. 2001; Poppele and Hozalski 2003; Simões et al. $2003 \mathrm{~b} ; 2005 \mathrm{~b}$ ) and studies concerning the effect of chemical agents on this parameter are even fewer. In this study, the biofilm mass remaining adhered to the cylinders after submission to the series of $\mathrm{N}^{\prime} \mathrm{Re}_{\mathrm{A}}$, and for the lower SDS concentrations, was considerably higher and dose dependent than observed for the control assay. It was expected that the surfactant properties of SDS would promote biofilm removal. Previous studies on Streptococcus mutans biofilms (Landa et al. 1999; Marcotte et al. 2004) showed that an increase of SDS concentration promoted an apparent partition of cross-linking electrostatic interactions, thereby diminishing biofilm cohesiveness. Chen and Stewart (2000) also proposed that SDS was implicated in the disruption of the hydrophobic interactions, involved in cross-linking the matrix of $P$. aeruginosa biofilms. Cross-linking interactions seem to be a significant aspect of maintenance of biofilm mechanical stability, as glutaraldehyde, an aldehydebased biocide known to cross-link biofilm proteins, increased the mechanical stability of $P$. fluorescens biofilms (Simões et al. 2003a). In the present study, only $7 \mathrm{mM}$ SDS, a concentration near the critical micellar concentration, decreased the amount of biofilm adhered to the cylinder, even though the differences were not statistically different from the untreated biofilms. The SDS effect on the mechanical stability of $P$. fluorescens biofilm seems to be strongly concentration-dependent, as the effect of low surfactant concentrations were quenched by the biofilm reactive sites. The overall effects of SDS on biofilm inactivation, viability, removal and recovery raises concerns about the potential impact of the increase in use of inefficient chemical agents and doses and the prevalence of resistance and cross-resistance (Davies 2003; Gilbert and McBain 2003).

In conclusion, SDS promoted partial inactivation of $P$. fluorescens biofilms generated in turbulent and laminar flow conditions. Due to the distinct biofilm phenotypic and the ionic nature of the surfactant, both turbulent and laminar flow-generated biofilms had similar susceptibility to SDS, with either of them being completely removed by the surfactant. Low concentrations of SDS promoted biofilm cohesion and thus decreased removal, leading to an increase in the mechanical stability of the biofilm. Following a temporary reduction effect (in terms of respiratory activity), biofilms recovered, a phenomenon that was more pronounced for turbulent flow-generated biofilms, giving rise to a mechanically stronger biofilm.

\section{Acknowledgements}

The authors acknowledge the financial support provided by the Portuguese Foundation for Science and Technology (Project CHEMBIO-POCI/BIO/61872/2004, PhD grant to Lúcia C. Simões and Post-doc grant to Manuel Simões).

\section{References}

APHA, AWWA, WPCF. 1989. In: Clesceri LS, Greenberg AE, Trussel RR, editors. Standard methods for the examination of water and wastewater. 17th ed. Washington (DC): American Public Health Association.

Boyle JD, Lappin-Scott HM. 2006. Quantification of the effect of flow rate on the rates of arrival and attachment to glass of Pseudomonas aeruginosa. Biofouling. 22:117-123.

Boyle JD, Lappin-Scott HM. 2007. The effect of flow direction and magnitude on the initial distribution of Pseudomonas aeruginosa cells attached to glass. Biofouling. 23:139-150. 
Chen X, Stewart PS. 2000. Biofilm removal caused by chemical treatments. Water Res. 34:4229-4233.

Cloete TE, Jacobs L, Brözel VS. 1998. The chemical control of biofouling in industrial water systems. Biodegradation. 9:23-37.

Costerton JW, Cheng K-J, Geesey GG, Ladd TI, Nickel JC, Dasgupta M, Marrie TJ. 1987. Bacterial biofilms in nature and disease. Annu Rev Microbiol. 41:435-464.

Davies D. 2003. Understanding biofilm resistance to antibacterial agents. Nat Rev Drug Discov. 2:114-122.

Denyer SP, Stewart GSAB. 1998. Mechanisms of action of disinfectants. Int Biodeterior Biodegr. 41:261-268.

Donlan RM, Costerton JW. 2002. Biofilms: survival mechanisms of clinically relevant microorganisms. Clin Microbiol Rev. 15:167-193.

Forsythe SJ, Hayes PR. 1998. Food hygiene, microbiology and HACCP. 3rd ed. Gaithersburg (Maryland, USA): Aspen. p. 327-371.

Fux CA, Costerton JW, Stewart PS, Stoodley P. 2005. Survival strategies of infectious biofilms. Trends Microbiol. 13:34-40.

Gilbert P, McBain AJ. 2003. Potential impact of increased use of biocides in consumer products on prevalence of antibiotic resistance. Clin Microbiol Rev. 16:189-208.

Gilbert P, Allison DG, McBain AJ. 2002. Biofilms in vitro and in vivo: do singular mechanisms influx crossresistance? J Appl Microbiol. 92:98S-110S.

Harrison JJ, Turner JR, Ceri H. 2005. Persister cells, the biofilm matrix and tolerance to metal cations in biofilm and planktonic Pseudomonas aeruginosa. Environ Microbiol. 7:981-994.

Johnston MD, Lambert RJW, Hanlon GW, Denyer SP. 2002. A rapid method for assessing the suitability of quenching agents for individual biocides as well as combinations. J Appl Microbiol. 92:784-789.

Jönsson B, Lindman B, Holmberg K, Kronberg B. 1998. Surfactants and polymers in aqueous solution. Chichester, UK: John Wiley.

Körstgens V, Flemming H-C, Wingender J, Borchard W. 2001. Uniaxial compression measurement device for investigation of the mechanical stability of biofilms. J Microbiol Meth. 46:9-17.

Landa AS, van de Belt-Gritter B, van der Mei HC, Busscher HJ. 1999. Recalcitrance of Streptococcus mutans biofilms towards detergent-stimulated detachment. Eur J Oral Sci. 107:236-243.

Lapidot A, Romling U, Sima Y. 2006. Biofilm formation and the survival of Salmonella Typhimurium on parsley. Int $\mathbf{J}$ Food Microbiol. 109:229-233.

Lewis K. 2001. Riddle of biofilm resistance. Antimicrob Agents Chemother. 45:999-1007.

MacDonald R, Santa M, Brözel VS. 2000. The response of a bacterial biofilm community in a simulated industrial cooling water system to treatment with an anionic dispersant. J Appl Microbiol. 89:225-235.

Mah TF, O’Toole GA. 2001. Mechanisms of biofilm resistance to antimicrobial agents. Trends Microbiol. 9:34-39.

Marcotte L, Therien-Aubin H, Sandt C, Barbeau J, Lafleur M. 2004. Solute size effects on the diffusion in biofilms of Streptococcus mutans. Biofouling. 20:189-201.
Mayer C, Moritz R, Kirschner C, Borchard W, Maibaum R, Wingender J, Flemming H-C. 1999. The role of intermolecular interactions: studies on model systems for bacterial biofilms. Int J Biol Macromol. 26:3-16.

Mcdougald D, Lin WH, Rice SA, Kjelleberg S. 2006. The role of quorum sensing and the effect of environmental conditions on biofilm formation by strains on Vibrio vulnificus. Biofouling. 22:161-172.

Møretrø T, Langsrud S. 2004. Listeria monocytogenes: biofilm formation and persistence in food-processing environments. Biofilms. 1:107-121.

Ohashi A, Harada H. 1994. Adhesion strength of biofilm developed in an attached-growth reactor. Water Sci Technol. 29:281-288.

Ohashi A, Harada H. 1996. A novel concept foe evaluation of biofilm adhesion strength by applying tensile force and shear force. Water Sci Technol. 34:201211.

Ohashi A, Koyama T, Syutsubo S, Harada H. 1999. A novel method for evaluation of biofilm tensile strength resisting erosion. Water Sci Technol. 39:261-268.

Pereira MO, Vieira MJ. 2001. Effects of the interactions between glutaraldehyde and the polymeric matrix on the efficacy of the biocide against Pseudomonas fluorescens biofilms. Biofouling. 17:93-101.

Pereira MO, Morin P, Vieira MJ, Melo LF. 2002. A versatile reactor for continuous monitoring of biofilm properties in laboratory and industrial conditions. Lett Appl Microbiol. 34:22-26.

Perez-Roa RE, Tompkins DT, Paulose M, Grimes CA, Anderson MA, Noguera DR. 2006. Effects of localised, low-voltage pulsed-electric fields on the development and inhibition of Pseudomonas aeruginosa biofilms. Biofouling. 22:383-390.

Poppele EH, Hozalski RM. 2003. Micro-cantilever method for measuring the tensile strength of biofilms and microbial flocs. J Microbiol Meth. 55:607-615.

Simões M, Pereira MO, Vieira MJ. 2003a. Monitoring the effects of biocide treatment of Pseudomonas fluorescens formed under different flow regimes. Water Sci Technol. 47:217-223.

Simões M, Pereira MO, Vieira MJ. 2003b. Effect of different concentrations of ortho-phthalaldehyde on biofilms formed by Pseudomonas fluorescens under different flow conditions. Biofouling. 19:287-295.

Simões M, Pereira MO, Vieira MJ. 2005a. Action of a cationic surfactant on the activity and removal of bacterial biofilms formed under different flow regimes. Water Res. 39:478-486.

Simões M, Pereira MO, Vieira MJ. 2005b. Effect of mechanical stress on biofilms challenged by different chemicals. Water Res. 39:5142-5152.

Simões M, Pereira MO, Vieira MJ. 2005c. Validation of respirometry as a short-term method to assess the toxic effect of a biocide. Biofouling. 47:217-223.

Simões M, Pereira MO, Machado I, Simões LC, Vieira MJ. 2006. Comparative antibacterial potential of selected aldehyde-based biocides and surfactants against planktonic Pseudomonas fluorescens. J Ind Microbiol Biotechnol. 33:741-749. 
Simões M, Pereira MO, Sillankorva S, Azeredo J, Vieira MJ. 2007. The effect of hydrodynamic conditions on the phenotype of Pseudomonas fluorescens biofilms. Biofouling. 23:249-258.

Spoering AL, Lewis K. 2001. Biofilms and planktonic cells of Pseudomonas aeruginosa have similar resistance to killing by antimicrobials. J Bacteriol. 183:6746-6751.

Stewart PS. 2003. Multicellular nature of biofilm protection from antimicrobial agents. In: McBain A, Allison D, Brading M, Rickard A, Verran J, Walker J, editors. Biofilm communities: order from chaos. Cardiff (UK): BioLine. p. 181-190.

Stoodley P, Lewandowski Z, Boyle JD, Lappin-Scott HM. 1999. Structural deformation of bacterial biofilms caused by short-term fluctuations in fluid shear: an in situ investigation of biofilm rheology. Biotech Bioeng. 65:83-92.
Sufya N, Allison D, Gilbert P. 2003. Clonal variation in maximum specific growth rate and susceptibility towards antimicrobials. J Appl Microbiol. 95:1261-1267.

Vieira MJ, Melo L, Pinheiro MM. 1993. Biofilm formation: hydrodynamic effects on internal diffusion and structure. Biofouling. 7:67-80.

Wiedmann M, Weilmeier D, Dineen SS, Ralyea R, Boor KJ. 2000. Molecular and phenotypic characterization of Pseudomonas spp. isolated from milk. Appl Environ Microbiol. 66:2085-2095. 